University of Wollongong

Research Online

Faculty of Engineering and Information

Faculty of Engineering and Information

Sciences - Papers: Part A

Sciences

$1-1-2015$

\title{
The role of forward osmosis and microfiltration in an integrated osmotic- microfiltration membrane bioreactor system
}

\author{
Wenhai Luo \\ University of Wollongong, wl344@uowmail.edu.au \\ Faisal I. Hai \\ University of Wollongong, faisal@uow.edu.au \\ Jinguo Kang \\ University of Wollongong, jkang@uow.edu.au \\ William E. Price \\ University of Wollongong, wprice@uow.edu.au \\ Long D. Nghiem \\ University of Wollongong, longn@uow.edu.au
}

See next page for additional authors

Follow this and additional works at: https://ro.uow.edu.au/eispapers

Part of the Engineering Commons, and the Science and Technology Studies Commons

Research Online is the open access institutional repository for the University of Wollongong. For further information contact the UOW Library: research-pubs@uow.edu.au 


\title{
The role of forward osmosis and microfiltration in an integrated osmotic- microfiltration membrane bioreactor system
}

\author{
Abstract \\ This study investigates the performance of an integrated osmotic and microfiltration membrane \\ bioreactor (O/MF-MBR) system for wastewater treatment and reclamation. The O/MF-MBR system \\ simultaneously used microfiltration (MF) and forward osmosis (FO) membranes to extract water from the \\ mixed liquor of an aerobic bioreactor. The MF membrane facilitated the bleeding of dissolved inorganic \\ salts and thus prevented the build-up of salinity in the bioreactor. As a result, sludge production and \\ microbial activity were relatively stable over 60 days of operation. Compared to MF, the FO process \\ produced a better permeate quality in terms of nutrients, total organic carbon, as well as hydrophilic and \\ biologically persistent trace organic chemicals (TrOCs). The high rejection by the FO membrane also led \\ to accumulation of hydrophilic and biologically persistent TrOCs in the bioreactor, consequently \\ increasing their concentration in the MF permeate. On the other hand, hydrophobic and readily \\ biodegradable TrOCs were minimally detected in both MF and FO permeates, with no clear difference in \\ the removal efficiencies between two processes.

\section{Disciplines} \\ Engineering | Science and Technology Studies

\section{Publication Details} \\ Luo, W., Hai, F. I.., Kang, J., Price, W. E., Nghiem, L. D. \& Elimelech, M. (2015). The role of forward osmosis \\ and microfiltration in an integrated osmotic-microfiltration membrane bioreactor system. Chemosphere, \\ $136125-132$.
}

\section{Authors}

Wenhai Luo, Faisal I. Hai, Jinguo Kang, William E. Price, Long D. Nghiem, and Menachem Elimelech 
1 The role of forward osmosis and microfiltration in an integrated osmotic-microfiltration membrane bioreactor system

\title{
Revised manuscript submitted to Chemosphere
}

April 2015

\begin{abstract}
Wenhai Luo ${ }^{\text {a }}$, Faisal I. Hai ${ }^{\text {a }}$, Jinguo Kang ${ }^{b}$, William E. Price ${ }^{b}$, Long D. Nghiem ${ }^{a^{*}}$,
\end{abstract} Menachem Elimelech ${ }^{\mathrm{c}}$

${ }^{a}$ Strategic Water Infrastructure Laboratory, School of Civil Mining and Environmental Engineering, University of Wollongong, Wollongong, NSW 2522, Australia

${ }^{b}$ Strategic Water Infrastructure Laboratory, School of Chemistry, University of Wollongong, Wollongong, NSW 2522, Australia

${ }^{c}$ Department of Chemical and Environmental Engineering, Yale University, New Haven, CT 06520-8286, United States

\footnotetext{
*Corresponding author: longn@uow.edu.au; Ph: +61 (2) 42214590.
} 


\section{Abstract}

14 This study investigates the performance of an integrated osmotic and microfiltration 15 membrane bioreactor (O/MF-MBR) system for wastewater treatment and reclamation. The 16 O/MF-MBR system simultaneously used microfiltration (MF) and forward osmosis (FO) 17 membranes to extract water from the mixed liquor of an aerobic bioreactor. The MF 18 membrane facilitated the bleeding of dissolved inorganic salts and thus prevented the build19 up of salinity in the bioreactor. As a result, sludge production and microbial activity were 20 relatively stable over 60 days of operation. Compared to MF, the FO process produced a 21 better permeate quality in terms of nutrients, total organic content, as well as hydrophilic and 22 biologically persistent TrOCs. The high rejection of the FO membrane also led to the 23 transport of several hydrophilic and biologically persistent TrOCs to the MF permeate. On 24 the other hand, hydrophobic and readily biodegradable TrOCs were minimally detected in 25 both MF and FO permeates, with no clear difference in the removal efficiencies between two 26 processes.

27 Key words: Osmotic membrane bioreactor (OMBR); Forward osmosis (FO); Microfiltration 28 (MF); Trace organic chemicals (TrOCs); Salinity build-up; 


\section{Introduction}

30 Water reuse is an important measure to tackle water scarcity and environmental pollution,

31 which are key factors hampering economic development and threating the nautral ecosystem

32 (Wintgens et al., 2008; Hochstrat et al., 2010). Safe and reliable water reuse requires

33 adequate removal of salts, nutrients, pathogenic agents, and trace organic chemicals (TrOCs)

34 from the reclaimed effluent. TrOCs are a diverse range of emerging organic chemicals of either anthropogenic or natural origin. They occur ubiqituously in munucipal wastewater at concentrations in the range of a few nanograms per litre $(\mathrm{ng} / \mathrm{L})$ to several micrograms per litre ( $\mu \mathrm{g} / \mathrm{L})$ (Luo et al., 2014). These TrOCs present arguably the most vexing challenge to practical potable water reuse (Wintgens et al., 2008; Lampard et al., 2010; Drewes et al., 2013; Luo et al., 2014).

Adequate removal of TrOCs is also essential to facilitate water reuse for agriculture production. It has been demonstrated that the occurrence of pharmaceuticals, such as carbamazepine and triclocarban, in reclaimed wastewater (Tanoue et al., 2012) and biosolids (Wu et al., 2012) used to grow fruits and vegetables can bio-accumulate in edible parts of these produces. Therefore, a major technical challenge for the water industry is to develop new treatment processes that can reliably and cost-effectively remove these TrOCs during water reuse.

Recent efforts in wastewater treatment and reuse have led to the emergence of a novel osmotic membrane bioreactor (OMBR) process (Achilli et al., 2009; Cornelissen et al., 2011; Nawaz et al., 2013), which integrates forward osmosis (FO) with the conventional activated sludge treatment technology. In the OMBR system, the osmotic pressure difference between the mixed liquor and draw solution (e.g. $\mathrm{NaCl}$ ) induces water diffusion through a semipermeable FO membrane. The FO membrane can effectively retain small organic contaminants in the bioreactor, thereby facilitating their subsequent biodegradation (Alturki et al., 2013; Coday et al., 2014). Indeed, recent studies have shown the excellent performance of OMBR for TrOC removal, particularly the compounds with relatively large molecule weight and/or featured with negative charge (Alturki et al., 2012; Lay et al., 2012; Holloway et al., 2014). Thus, OMBR can potentially produce high quality reclaimed water for potable reuse, irrigation, or direct discharge in environmentally sensitive areas.

59 Despite the potential of OMBR, salinity build-up in the bioreactor caused by high rejection of

60 the FO membrane and reverse transport of the draw solution remains a technical challenge for 
61 its further development (Van der Bruggen and Patricia, 2015). The high bioreactor salinity can reduce the driving force for water transport (Lay et al., 2010). Sludge characteristics and microbial community can also be altered with the elevated bioreactor salinity and subsequently worsen the biological treatment and membrane performance (Qiu and Ting, 2013). A short sludge retention time (SRT) is expected to control the build-up of salinity in the bioreactor. However, in an OMBR system with an operating SRT of 10 days, the bioreactor salinity still increased substantially, exerting inhibition on the microbial activity (Wang et al., 2014a). The short SRT could also adversely affect the biological performance (Grelier et al., 2006) and increase the cost for waste sludge disposal. Several studies have recently proposed the integration of an microfiltration (MF) or ultrafiltration (UF) process with OMBR to bleed out inorganic salts from the bioreactor (Holloway et al., 2014, 2015; Wang et al., 2014b). By applying the approach, Holloway et al. $(2014,2015)$ showed a stable operation of a pilot UFO-MBR treating raw domestic wastewater over a period of four months. Removal to below the detection limit was reported for 15 out of 20 TrOCs investigated in their study in 2014 using a pilot reverse osmosis process for draw solution and clean water recoveries (Holloway et al., 2014).

Building upon the existing literature on this topic, we aimed to evaluate the performance of an integrated osmotic and microfiltration membrane bioreactor (O/MF-MBR) by specifically comparing permeate qualities between the FO and MF processes and examining sludge stability in the bioreactor. The system performance was also assessed in terms of water flux, bioreactor salinity, and membrane fouling. TrOC removal was related to their hydrophobicity and molecular structures to mechanistically elucidate their fate within the integrated $\mathrm{O} / \mathrm{MF}$ MBR system. The interaction between FO and MF in the integrated system with regards to the fate and removal of TrOCs was also discussed.

\section{Materials and methods}

\subsection{Representative trace organic chemicals}

A stock solution containing 30 representative TrOCs (Table S1, Supplementary Data) were prepared in pure methanol and stored at $-18{ }^{\circ} \mathrm{C}$ in the dark. The stock solution was used within less than a month. These TrOCs were selected to represent four major groups of chemicals of emerging concern - pharmaceutical and personal care products, endocrine disrupting compounds, pesticides, and industrial chemicals - that are ubiquitous in municipal 
93 weight, and functional groups (Table S1, Supplementary Data). Hydrophobicity of an organic 94 compound can be measured by $\log \mathrm{D}$, which is the effective octanol-water partition coefficient at a given solution $\mathrm{pH}$ (Nghiem and Coleman, 2008). Based on their Log D values at $\mathrm{pH}$ of 7 , the selected TrOCs can be classified as hydrophilic (i.e. $\log \mathrm{D}_{\mathrm{pH}} 7<3$ ) or hydrophobic (i.e. $\log \mathrm{D}_{\mathrm{pH}}>3$ ).

98

99

\subsection{FO and MF membranes}

A flat-sheet, cellulose based membrane supplied by Hydration Technology Innovations (HTI, Albany, USA) was used in the FO process. The FO membrane is composed of a cellulose triacetate active (CTA) layer reinforced by a polyester mesh for mechanical support (McCutcheon and Elimelech, 2008). It is noteworthy that thin film composite (TFC) FO membranes with embedded polyester screen support have also been released by HTI and several other manufactures in recent years. Both CTA and TFC membranes have their own positive attributes. Findings from this study are specific to the OMBR process rather than specific membrane properties and thus applicable to all types of FO membranes.

A hollow fibre, polyvinylidene fluoride MF membrane module from Mitsubishi Rayon Engineering (Tokyo, Japan) was submerged in the bioreactor. The effective surface area and nominal pore size of the MF membrane were $740 \mathrm{~cm}^{2}$ and $0.4 \mu \mathrm{m}$, respectively.

\subsection{Experimental system}

The integrated O/MF-MBR system used in this study was composed of a cross-flow FO configuration, a submerged MF membrane module, and a $10 \mathrm{~L}$ aerobic bioreactor (Fig. 1). An electrical air pump (Heilea, Ningbo, China) was used to continuously aerate the reactor via a coarse diffuser. A Masterflex peristaltic pump (Cole-Parmer, Vernon Hills, USA) was used to draw permeate through the MF membrane with an operation on/off time of $14 / 1 \mathrm{~min}$. Transmembrane pressure (TMP) of the MF membrane was continuously monitored by a high resolution $( \pm 0.1 \mathrm{kPa})$ pressure sensor (Extech Instruments, Nashua, USA).

A detailed description of the cross-flow FO configuration is available elsewhere (Alturki et al., 2012). Briefly, the FO configuration comprised two semi-cells made of acrylic plastic and a draw solution delivery and control equipment. The FO membrane was placed between two semi-cells to seal the feed and draw solution channels with a length, width, and depth of 145 , 95 , and $2 \mathrm{~mm}$, respectively. The effective membrane surface area was $138 \mathrm{~cm}^{2}$, with the active layer facing the feed channel (i.e. FO mode). The mixed liquor in the bioreactor was 
124 circulated to the feed channel by a Masterflex peristaltic pump (Cole-Parmer, Vernon Hills, 125 USA). On the other side, a gear pump (Micropump, Vancouver, USA) was used to circulate a 126 draw solution to the draw solution channel. The circulation flow rate of both the feed and 127 draw solutions was $1 \mathrm{~L} / \mathrm{min}$ (i.e. a cross-flow velocity of $9 \mathrm{~cm} / \mathrm{s}$ ) monitored by rotameters 128 (Cole-Parmer, Vernon Hills, USA). The draw solution reservoir was placed on a digital 129 balance connected to a computer. During the experimental period, the draw solution 130 concentration was kept constant by a conductivity controller equipped with a conductivity 131 probe and a Masterflex peristaltic pump to automatically dose a concentrated draw solution to 132 the draw solution reservoir. The controller accuracy was $0.1 \mathrm{mS} / \mathrm{cm}$ (i.e. $0.05 \mathrm{~g} / \mathrm{L} \mathrm{NaCl}$ ). 133 Both the concentrated and working draw solution reservoirs were placed on the same digital 134 balance to avoid experimental errors by the concentration control equipment.

\section{[FIGURE 1]}

\section{$136 \quad 2.4$ Experimental protocol}

137 A submerged MF-MBR system was first initiated to seed the bioreactor with activated sludge 138 from the Wollongong Wastewater Treatment Plant (Wollongong, Australia). The initial 139 mixed liquor suspended solid (MLSS) concentration in the bioreactor was approximately 5 $140 \mathrm{~g} / \mathrm{L}$. Synthetic wastewater was used to simulate medium strength municipal sewage and 141 consisted of $100 \mathrm{mg} / \mathrm{L}$ glucose, $100 \mathrm{mg} / \mathrm{L}$ peptone, $17.5 \mathrm{mg} / \mathrm{L} \mathrm{KH}_{2} \mathrm{PO}_{4}, 17.5 \mathrm{mg} / \mathrm{L} \mathrm{MgSO}_{4}$, $14210 \mathrm{mg} / \mathrm{L} \mathrm{FeSO}_{4}, 225 \mathrm{mg} / \mathrm{L} \mathrm{CH}_{3} \mathrm{COONa}$ and $35 \mathrm{mg} / \mathrm{L}$ urea. The MF-MBR system was 143 stabilized in a temperature-controlled room $\left(22 \pm 1{ }^{\circ} \mathrm{C}\right)$ at a working volume of $6 \mathrm{~L}$, a 144 hydraulic retention time (HRT) of $24 \mathrm{~h}$, and a dissolved oxygen concentration (DO) of $5 \pm 1$ $\mathrm{mg} / \mathrm{L}$. Compared to a typical MBR system, a longer HRT was used in this study to maintain a

146 relatively low water flux to minimize the membrane fouling. The relatively high aeration rate 147 of $8 \mathrm{~L} / \mathrm{min}$ used here to prevent sludge settlement and scour the membrane surface also 148 resulted in a higher DO concentration than that in a typical MBR system. No sludge was 149 wasted (except for weekly sampling of $90 \mathrm{~mL}$ mixed liquor) to systematically investigate the 150 build-up of salinity in the bioreactor. Stability of the bioreactor was determined by sludge 151 production, biomass activity, and removal of organic matter and nutrients. In practice, regular 152 sludge withdrawal can alleviate salinity build-up to some extent.

153 Once stabilized, the cross-flow FO process was connected to the bioreactor to form an 154 integrated O/MF-MBR system. At the same time, the TrOC stock solution was spiked to the 155 influent to obtain $5 \mu \mathrm{g} / \mathrm{L}$ of each of the 30 compounds. The integrated system was operated 
continuously for 60 days under the conditions as mentioned above. To minimize the biosolids

157 blockage in the narrow feed channel of the cross-flow FO system, the initial MLSS

158 concentration in the bioreactor was adjusted to $2 \mathrm{~g} / \mathrm{L}$. Given the unstable water flux of the FO

159 process, the permeate flux of MF was adjusted daily to maintain a constant HRT of $24 \mathrm{~h}$. The

160 draw solution and concentrated draw solution were 58.5 and $351 \mathrm{~g} / \mathrm{L} \mathrm{NaCl}$, respectively. The

161 draw solution was replaced every day to avoid overflow and contaminant accumulation. The

162 concentrated draw solution was also added manually on a daily basis. Membrane cleaning 163 was not conducted during this study.

\subsection{Analytical methods}

165 Total organic carbon (TOC) and total nitrogen (TN) of the influent, mixed liquor supernatant,

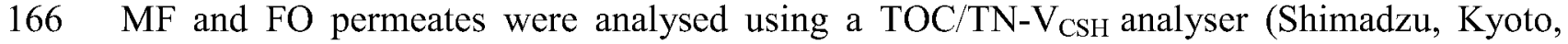
167 Japan). Orthophosphate $\left(\mathrm{PO}_{4}{ }^{3-}\right)$ was measured by a Flow Injection Analysis system 168 (QuichChem 8500, Lachat, USA). MLSS and mixed liquor volatile suspended solid (MLVSS) concentrations were determined following the Standard Methods for the Examination of

170 Water and Wastewater. Specific oxygen uptake rate (SOUR) of the sludge was tested based on the technique described by Choi et al. (2007). Mixed liquor pH and conductivity were measured using an Orion 4-Star Plus pH/conductivity meter (Thermo Scientific, Waltham, 173 USA).

174 TrOC concentrations in the feed, mixed liquor supernatant, MF permeate, and draw solution were determined weekly using an analytical method described by Hai et al. (2011). The method involved solid phase extraction and derivation, followed by gas chromatographymass spectrometry (GC-MS) analysis using a Shimadzu GC-MS system (Kyoto, Japan). In this study, the MF and FO processes were operated simultaneously to extract water from

179 the bioreactor. Permeate samples could thus be obtained separately from the MF-MBR and 180 OMBR channels (i.e. bioreactor-MF and -FO streams, respectively). Against the feed 181 contaminant concentration, the removal efficiency through the MF-MBR channel was 182 defined as:

183 $R=\left(1-\frac{C_{M F}}{C_{F e e d}}\right) \times 100 \%$ where, $C_{\text {Feed }}$ and $C_{\mathrm{MF}}$ were contaminant concentrations in the feed and $\mathrm{MF}$ permeate, respectively. Unlike the MF process, contaminants permeated through the FO membrane 
were diluted by the draw solution. The dilution factor $(D F)$ was calculated using a mass balance:

$188 \quad D F=\frac{V_{D S}}{V_{F O}}$

where, $V_{\mathrm{DS}}$ and $V_{\mathrm{FO}}$ were draw solution and FO permeate volumes until sampling time. As noted above, to avoid solution overflow and contaminant accumulation, the draw solution was replaced every day. Thus, the overall removal through the OMBR channel was defined as:

193

$$
R=\left(1-\frac{C_{D S}}{C_{F e \mathrm{ed}}} D F\right) \times 100 \%
$$

194 where $C_{\mathrm{DS}}$ was contaminant concentrations in the draw solution reservoir.

195 In this study, TrOC accumulation in biosolids was not considered for removal assessment

196 because only compounds in the aqueous phase could transport through the MF and FO

197 membranes. It is also noteworthy that TrOC removal here only indicates the disappearance of 198 parent molecules but not necessarily complete mineralization. Indeed, biodegradation of certain TrOCs would produce stable intermediates/metabolites in the bioreactor and permeates. However, detailed discussion of these aspects is beyond the scope of this study.

\section{3. Results and discussion}

\subsection{Process performance}

\subsubsection{Salinity build-up, water flux, and membrane fouling}

204 The integration of the MF membrane into OMBR prevented the build-up of salinity in the 205 bioreactor, because dissolved inorganic salts were readily permeable through the microporous membrane (Fig. 2). After a small increase in the first week, the mixed liquor conductivity stabilized at approximately $700 \mu \mathrm{S} / \mathrm{cm}$ (i.e. a salinity of $0.4 \mathrm{~g} / \mathrm{L} \mathrm{NaCl}$ ). The result compares favourably with our previous study where a rapid increase in the mixed liquor conductivity from 268 to $8270 \mu \mathrm{S} / \mathrm{cm}$ was observed within seven days using the

210 similar experimental configuration and conditions without housing the submerged MF

211 membrane in the bioreactor (Alturki et al., 2012).

213 Two distinct stages of water flux decline could be observed in the FO process with time (Fig. 214 2). The water flux decreased rapidly from 6.5 to $3.4 \mathrm{~L} / \mathrm{m}^{2} \mathrm{~h}$ within the first week mainly 
215 because of salinity build-up in the bioreactor and membrane fouling. With the decrease in the 216 bioreactor salinity, the water flux of the FO process decreased slightly and then stabilized at 217 approximately $1.7 \mathrm{~L} / \mathrm{m}^{2} \mathrm{~h}$ from day 45 onward. The elevated salinity could increase the 218 osmotic pressure in the mixed liquor side and thus reduce the driving force for water 219 transport. On the other hand, high salinity could lead to double layer compression and reduce 220 electrostatic interaction among the macromolecule functional groups, resulting in a thicker 221 and more compact fouling layer (Nghiem et al., 2005). Indeed, a thick cake layer was 222 observed on the membrane surface at a feed cross-flow velocity of $9 \mathrm{~cm} / \mathrm{s}$ in this study (Fig. 223 S1, Supplementary Data). The fouling layer could increase the hydraulic resistance to water 224 permeation and cause severe concentration polarization adjacent to membrane surface, 225 thereby reducing the water flux (Hoek and Elimelech, 2003; Boo et al., 2012).

226 It is noteworthy that the stable water flux of approximately $1.7 \mathrm{~L} / \mathrm{m}^{2} \mathrm{~h}$ was much lower than 227 that observed by Holloway et al. (2015). The different flux behaviours between the two 228 studies could be attributed to the difference in hydrodynamics adjacent to membrane surface 229 between the submerged and cross-flow FO systems. In our cross-flow FO system, particulates 230 in mixed liquor were prone to adhere to the membrane surface in the narrow feed channel, 231 particularly at a low feed cross-flow velocity of $9 \mathrm{~cm} / \mathrm{s}$.

232 The TMP value of the MF membrane only increased to $5 \mathrm{kPa}$ ( 0.05 bar) by the end of the 233 experiment (Fig. S2, Supplementary Data), indicating a negligible membrane fouling. The 234 low membrane fouling could be attributed to the small water flux and high aeration rate 235 applied in this study. Over 60 days of experiment, the water flux of MF was adjusted from

2361.6 to $2.6 \mathrm{~L} / \mathrm{m}^{2} \mathrm{~h}$. By considering the gradual flux decline in the FO process, this flow 237 adjustment was necessary to keep a constant HRT of $24 \mathrm{~h}$ during the entire experimental 238 period. On the other hand, the low MLSS concentration in the bioreactor $(2-3.3 \mathrm{~g} / \mathrm{L})$ could 239 also minimize the membrane fouling.

\subsubsection{Biological performance}

241 Biological performance of the integrated O/MF-MBR system was assessed with regards to 242 the removal of basic contaminants (i.e. TOC, TN, and $\mathrm{PO}_{4}{ }^{3-}-\mathrm{P}$ ), sludge production, and 243 biological activity. The removal of basic contaminants was stable after a short-term salinity 244 build-up in the bioreactor (Fig. 3). The stable removal can also be determined by the small 245 standard deviation of these contaminant concentrations in different units of O/MF-MBR 246 during the course of the experiment (Table S2, Supplementary Data). 
247 Due to the high rejection of the FO membrane, permeate quality of FO was superior to that of

248 MF, particularly in terms of TN and $\mathrm{PO}_{4}{ }^{3-}-\mathrm{P}$ concentrations (Fig. 3). The removal of TOC

249 from the OMBR channel was over $98 \%$ during the entire experimental period (Fig. 3a). The

250 result is consistent with that reported by Hancock et al. (2013). Given the excellent removal

251 of TOC from the bioreactor (indicated by low TOC concentration in the mixed liquor

252 supernatant), the benefits of FO over MF were not significant. However, the removal of TN

253 through the MF-MBR channel only varied in the range of $20-65 \%$, with relatively high

254 concentration in the permeate (Fig. 3b). Since the removal of TN in aerobic bioreactors

255 occurs mainly via assimilation to the biomass (Hai et al., 2014), it was not surprised to

256 observe the relatively low and unstable removal. By contrast, TN removal from the OMBR

257 channel ranged from 60 to $90 \%$, although there was a small decline from day 40 onward. This

258 decline was likely due to the incomplete rejection of $\mathrm{NH}_{4}{ }^{+}-\mathrm{N}$ and accumulated $\mathrm{NO}_{\mathrm{x}}{ }^{-}-\mathrm{N}$ by the

259 FO membrane (Irvine et al., 2013; Luo et al., 2015). A small and variable removal through

260 the MF-MBR channel was also observed for $\mathrm{PO}_{4}{ }^{3-}-\mathrm{P}$ (Fig. 3c), possibly due to the low

261 biomass assimilation and/or phosphorus precipitation under the nearly neutral $\mathrm{pH}$ condition

262 in the bioreactor (Qiu and Ting, 2014). Nevertheless, $\mathrm{PO}_{4}{ }^{3-}-\mathrm{P}$ could not be detected in the FO

263 permeate. Indeed, the $\mathrm{FO}$ membrane can almost completely retain $\mathrm{PO}_{4}{ }^{3-}-\mathrm{P}$ due to the large

264 hydrated radius and negative charge of the orthophosphate ions (Holloway et al., 2007).

[FIGURE 3]

266 The MLSS concentration gradually increased with time after a slight decrease in the first week (Fig. 4). The small decrease in the MLSS concentration at the beginning was possibly due to the inhibitory effects of the elevated bioreactor salinity on microbial mass. This inhibition was also evidenced by a reduction in biomass activity as indicated by the SOUR of the sludge (Fig. S3, Supplementary Data). With the bioreactor salinity stabilizing at a relatively low level $(0.4 \mathrm{~g} / \mathrm{L} \mathrm{NaCl})$, the sludge concentration in the bioreactor increased gradually with the MLVSS/MLSS ratio of $0.75 \pm 0.05$ from day 7 onward. At the same time, the SOUR of the sludge also increased and subsequently levelled off at $4.5 \mathrm{mg} \mathrm{O} / \mathrm{g} \mathrm{MLVSS}$ $\mathrm{h}$. This stable SOUR value is in good agreement with that reported previously in conventional

275 MBRs (Han et al., 2005; Choi et al., 2007).

[FIGURE 4] 
The removal of most TrOCs selected here was stable during the entire course of the experiment (Fig. 5). There are only six exceptions, namely, clofibric acid, atrazine, carbamazepine, propoxur, diclofenac and fenoprop. The removal of these six compounds is shown as a function of time in Fig. 6. During biological treatment, TrOC removal can be evaluated using a qualitative predictive framework developed by Tadkaew et al. (2011) based on their molecular properties, such as hydrophobicity and functional groups. According to the scheme, TrOCs investigated in this study could be generally classified as hydrophobic (i.e. $\log \mathrm{D}_{\mathrm{pH} 7}>3$ ) or hydrophilic (i.e. $\log \mathrm{D}_{\mathrm{pH}}<3$ ) (section 2.1 ).

\subsubsection{Hydrophobic TrOCs}

Of 30 TrOCs selected in this study, all eleven hydrophobic compounds could be effectively removed ( $>85 \%$ ) from both OMBR and MF-MBR channels (Fig. 5). Previous studies have demonstrated the excellent removal of these hydrophobic TrOCs during biological treatment (Radjenović et al., 2009; Nguyen et al., 2012). Due to the high hydrophobicity of these compounds, they can easily absorb on the activated sludge and thereby facilitate their biodegradation (transformation) in the bioreactor (Tadkaew et al., 2011). As a result, apart from bisphenol A and octocrylene, there was no clear difference in the concentration of these hydrophobic TrOCs between the MF and FO permeates (Fig. 5). It is noteworthy that bisphenol A and octocrylene concentrations in the FO permeate were higher than those in the MF permeate. Their high concentrations in the FO permeate were possibly due to cakeenhanced concentration polarization caused by the foulant layer on the membrane surface (Vogel et al., 2010). These two compounds are hydrophobic. Thus, their accumulation adjacent to the membrane surface due to cake-enhanced concentration polarization could enhance their transport across the FO membrane via hydrophobic interactions (Nghiem et al., 2004). Further studies are necessary to ascertain the effects of the sludge cake layer on the rejection of TrOCs, particularly the hydrophobic compounds, in the FO process.

\subsubsection{Hydrophilic TrOCs}

306 Significant variation in the removal of hydrophilic TrOCs was observed from both MF-MBR and OMBR channels. By accounting for the relatively large pores of the MF membrane, their removal through the MF-MBR channel was mainly governed by the activated sludge. Indeed, previous studies have shown a large variation in the removal of hydrophilic TrOCs in 
conventional MBRs, which was determined by their intrinsic biodegradability due to their

311 weak adsorption onto biosolids (Tadkaew et al., 2011). In this study, the removal of six very

312 hydrophilic TrOCs (i.e. Log $\mathrm{D}_{\mathrm{pH}} 7<1$ ), including salicylic acid, metronidazole, ketoprofen,

313 naproxen, primidone, and ibuprofen, was higher than 85\% through the MF-MBR channel.

314 The excellent removal of these compounds could be attributed to the presence of strong

315 electron donating functional groups, such as amine and hydroxyl groups, in their molecular

316 structures (Table S1). Containing these functional groups allowed compounds easily to be

317 electrophilically attacked by oxygenases from the aerobic bacteria. The oxygenases are key

318 reactants responsible for biodegradation of organic compounds (Kanazawa et al., 2003;

319 Tadkaew et al., 2011). Since these hydrophilic TrOCs could be effectively removed in the

320 bioreactor, the benefits of FO over MF were not significant (Fig. 5). It is noted that the

321 removal of salicylic acid from the OMBR channel was slightly lower than that through the

322 MF-MBR channel. The exact reason is still unclear but it could be attributed to the effects of

323 cake-enhanced concentration polarization in the FO process as noted above.

324 Due to the high rejection of the FO membrane, the removal through the OMBR channel was more effective than that from the MF-MBR channel for the six hydrophilic TrOCs shown in

326 Fig. 6. The removal of these compounds was low and highly variable through the MF-MBR

327 channel because of their resistance to biodegradation. Tadkaew et al. (2011) have attributed

328 their low biodegradation to the presence of one or more strong electron withdrawing

329 functional group (e.g. chlorine, amide and nitro groups) and/or the absence of strong electron

330 donating functional groups in their molecular structures. Despite the low removal of these

331 compounds in the bioreactor, their high rejection by the FO membrane ensured excellent

332 removal from the OMBR channel. The benefits of the FO membrane for TrOC rejection have

333 already been highlighted in several recent studies (Alturki et al., 2013; Coday et al., 2014).

334 With the exception of clofibric acid, the rejection of these hydrophilic and biologically 335 persistent TrOCs by the FO membrane increased their permeation through the MF membrane 336 and thus reduced the removal by the MF-MBR channel (Fig. 6). The removal of clofibric acid 337 via the MF-MBR channel gradually increased with time, although some fluctuations were 338 observed. The reason for this phenomenon is not clear, possibly due to an enhanced 339 biodegradation with the increased MLSS concentration in the bioreactor (Cirja et al., 2008).

340 Of six biologically persistent compounds noted above, the removal of atrazine by the OMBR 341 channel was also observed to decrease gradually with time. Atrazine has moderate 342 hydrophobicity $\left(\log \mathrm{D}_{\mathrm{pH} 7}=2.6\right)$, and thus the observed low and reduced removal could be 
343 attributed to its adsorption and partitioning into the membrane surface followed by a

344 diffusion through the membrane (Nghiem et al., 2004).

345

346

347

348

350

351

352

353

354

355

356

357

358

359

360

361

362

363

364

365

366

367

368

369

370

371

372

373

\section{Conclusion}

This study compared the water quality of the FO and MF permeates in an integrated $\mathrm{O} / \mathrm{MF}-$ MBR system regarding the concentration of TOC, TN, $\mathrm{PO}_{4}{ }^{3-}-\mathrm{P}$ and TrOCs. The FO permeate had a higher water quality than the MF permeate due to the effective rejection of the FO membrane. The concentration of hydrophobic TrOCs and hydrophilic compounds containing strong electron donating functional groups was low in both MF and FO permeates as they could be well removed by the activated sludge. However, the concentration of hydrophilic and biologically persistent TrOCs which contained strong electron withdrawing functional groups in the FO permeate was much lower than that in the MF permeate. In addition, due to the high rejection of the FO membrane, these hydrophilic and biologically persistent TrOCs could accumulate in the bioreactor and be transferred into the MF permeate. Thus, the water flux ratio between MF and FO can be optimised to reduce salinity build-up in the bioreactor while ensuring adequate MF permeate quality.

\section{Acknowledgement}

This research was supported under Australian Research Council's Discovery Project funding scheme (project DP140103864). The authors would like to thank the Chinese Scholarship Council and the University of Wollongong for the PhD scholarship support to Wenhai Luo.

\section{References}

Achilli, A., Cath, T.Y., Marchand, E.A., Childress, A.E. 2009. The forward osmosis membrane bioreactor: A low fouling alternative to MBR processes. Desalination, 239 (13), 10-21.

Alturki, A.A., McDonald, J., Khan, S.J., Hai, F.I., Price, W.E., Nghiem, L.D. 2012. Performance of a novel osmotic membrane bioreactor (OMBR) system: Flux stability and removal of trace organics. Bioresour. Technol., 113, 201-206.

Alturki, A.A., McDonald, J.A., Khan, S.J., Price, W.E., Nghiem, L.D., Elimelech, M. 2013. Removal of trace organic contaminants by the forward osmosis process. Sep. Purif. Technol., 103, 258-266.

Boo, C., Lee, S., Elimelech, M., Meng, Z., Hong, S. 2012. Colloidal fouling in forward osmosis: Role of reverse salt diffusion. J. Membr. Sci., 390-391, 277-284. 
Choi, J.H., Lee, S.H., Fukushi, K., Yamamoto, K. 2007. Comparison of sludge characteristics and PCR-DGGE based microbial diversity of nanofiltration and microfiltration membrane bioreactors. Chemosphere, 67 (8), 1543-1550.

Cirja, M., Ivashechkin, P., Schäffer, A., Corvini, P.F.X. 2008. Factors affecting the removal of organic micropollutants from wastewater in conventional treatment plants (CTP) and membrane bioreactors (MBR), Rev. Environ. Sci. Biotechnol., 7 (1), 61-78.

Coday, B.D., Yaffe, B.G.M., Xu, P., Cath, T.Y. 2014. Rejection of trace organic compounds by forward osmosis membranes: A literature review. Environ. Sci. Technol., 48 (7), 36123624.

Cornelissen, E.R., Harmsen, D., Beerendonk, E.F., Qin, J.J., Oo, H., de Korte, K.F., Kappelhof, J.W.M.N. 2011. The innovative osmotic membrane bioreactor (OMBR) for reuse of wastewater. Water Sci. Technol., 63 (8), 1557-1565.

Drewes, J.E., Anderson, P., Denslow, N., Olivieri, A., Schlenk, D., Snyder, S.A., Maruya, K.A. 2013. Designing monitoring programs for chemicals of emerging concern in potable reuse : What to include and what not to include? Wate Sci. and Tech., 67 (2), 433-439.

Grelier, P., Rosenberger, S., Tazi-Pain, A. 2006. Influence of sludge retention time on membrane bioreactor hydraulic performance. Desalination, 192 (1-3), 10-17.

Hai, F.I., Tessmer, K., Nguyen, L.N., Kang, J., Price, W.E., Nghiem, L.D. 2011. Removal of micropollutants by membrane bioreactor under temperature variation. J. Membr. Sci., 383 (1), 144-151.

Hai, F.I., Yamamoto, K., Lee, C.H. 2014. Membrane Biological Reactors: Theory, Modeling, Design, Management and Applications to Wastewater Reuse. IWA Publishing, London.

Han, S.S., Bae, T.H., Jang, G.G., Tak, T.M. 2005. Influence of sludge retention time on membrane fouling and bioactivities in membrane bioreactor system. Process Biochem., 40 (7), 2393-2400.

Hancock, N.T., Xu, P., Roby, M.J., Gomez, J.D., Cath, T.Y. 2013. Towards direct potable reuse with forward osmosis: Technical assessment of long-term process performance at the pilot scale. J. Membr. Sci., 445, 34-46.

Hochstrat, R., Wintgens, T., Kazner, C., Melin, T., Gebel, J. 2010. Options for water scarcity and drought management-the role of desalination. Desalin. Water Treat., 18 (1-3), 96-102.

Hoek, E.M.V., Elimelech, M. 2003. Cake-enhanced concentration polarization: A new fouling mechanism for salt-rejecting membranes. Environ. Sci. Technol., 37 (24), 55815588. 
Holloway, R.W., Childress, A.E., Dennett, K.E., Cath, T.Y. 2007. Forward osmosis for concentration of anaerobic digester centrate. Water Res., 41 (17), 4005-4014.

Holloway, R.W., Regnery, J., Nghiem, L.D., Cath, T.Y. 2014. Removal of trace organic chemicals and performance of a novel hybrid ultrafiltration-osmotic membrane bioreactor. Environ. Sci. Technol., 48 (18), 10859-10868.

Holloway, R.W., Wait, A.S., Fernandes da Silva, A., Herron, J., Schutter, M.D., Lampi, K., Cath, T.Y. 2015. Long-term pilot scale investigation of novel hybrid ultrafiltrationosmotic membrane bioreactors. Desalination, 363, 64-74.

Irvine, G.J., Rajesh, S., Georgiadis, M., Phillip, W.A. 2013. Ion selective permeation through cellulose acetate membranes in forward osmosis. Environ. Sci. Technol., 47 (23), 13745 13753.

Kanazawa, H., Okada, A., Higaki, M., Yokota, H., Mashige, F., Nakahara, K. 2003. Stereospecific analysis of omeprazole in human plasma as a probe for CYP2C19 phenotype. J. Pharm. Biomed. Anal., 30 (6), 1817-1824.

Lampard, J., Leusch, F.D.L., Roiko, A., Chapman, H.F. 2010. Contaminants of concern in recycled water. Water, $37(8), 54-60$.

Lay, W.C.L., Liu, Y., Fane, A.G. 2010. Impacts of salinity on the performance of high retention membrane bioreactors for water reclamation: A review. Water Res., 44 (1), 21 40.

Lay, W.C.L., Zhang, Q., Zhang, J., McDougald, D., Tang, C., Wang, R., Liu, Y., Fane, A.G. 2012. Effect of pharmaceuticals on the performance of a novel osmotic membrane bioreactor (OMBR). Sep. Purif. Technol., 47 (4), 543-554.

Luo, W., Hai, F.I., Price, W.E., Nghiem, L.D. 2015. Water extraction from mixed liquor of an aerobic bioreactor by forward osmosis: Membrane fouling and biomass characteristics assessment. Sep. Purif. Technol., 145, 56-62.

Luo, Y., Guo, W.S., Ngo, H.H., Nghiem, L.D., Hai, F.I., Zhang, J., Liang, S., Wang, X.C.C. 2014. A review on the occurrence of micropollutants in the aquatic environment and their fate and removal during wastewater treatment. Sci. Total Environ., 473, 619-641.

McCutcheon, J.R., Elimelech, M. 2008. Influence of membrane support layer hydrophobicity on water flux in osmotically driven membrane processes. J. Membr. Sci., 318 (1), 458466.

Nawaz, M.S., Gadelha, G., Khan, S.J., Hankins, N. 2013. Microbial toxicity effects of reverse transported draw solute in the forward osmosis membrane bioreactor (FO-MBR). J. Membr. Sci., 429, 323-329. 
Nghiem, L.D., Coleman, P.J. 2008. NF/RO filtration of the hydrophobic ionogenic compound triclosan: Transport mechanisms and the influence of membrane fouling. Sep. Purif. Technol., 62 (3), 709-716.

Nghiem, L.D., Schäfer, A.I., Elimelech, M. 2005. Nanofiltration of hormone mimicking trace organic contaminants. Sep. Purif. Technol., 40 (13), 2633-2649.

Nghiem, L.D., Schäfer, A.I., Elimelech, M. 2004. Removal of natural hormones by nanofiltration membranes: Measurement, modeling, and mechanisms. Environ. Sci. Technol., 38 (6), 1888-1896.

Nguyen, L.N., Hai, F.I., Kang, J., Price, W.E., Nghiem, L.D. 2012. Removal of trace organic contaminants by a membrane bioreactor-granular activated carbon (MBR-GAC) system. Bioresour. Technol., 113, 169-173.

Qiu, G.L., Ting, Y.P. 2014. Direct phosphorus recovery from municipal wastewater via osmotic membrane bioreactor (OMBR) for wastewater treatment. Bioresour. Technol., $170,221-229$.

Qiu, G.L., Ting, Y.P. 2013. Osmotic membrane bioreactor for wastewater treatment and the effect of salt accumulation on system performance and microbial community dynamics. Bioresour. Technol., 150, 287-297.

Radjenović, J., Petrović, M., Barceló, D. 2009. Fate and distribution of pharmaceuticals in wastewater and sewage sludge of the conventional activated sludge (CAS) and advanced membrane bioreactor (MBR) treatment. Water Res., 43 (3), 831-841.

Tadkaew, N., Hai, F.I., McDonald, J.A., Khan, S.J., Nghiem, L.D. 2011. Removal of trace organics by MBR treatment: The role of molecular properties. Water Res., 45 (8), 24392451.

Tanoue, R., Sato, Y., Motoyama, M., Nakagawa, S., Shinohara, R., Nomiyama, K. 2012. Plant uptake of pharmaceutical chemicals detected in recycled organic manure and reclaimed wastewater. J. Agric. Food. Chem., 60 (41), 10203-10211.

Van der Bruggen, B., Patricia, L. 2015. Forward osmosis: Understanding the hype. Rev. Chem. Eng., 31 (1), 1-12.

Vogel, D., Simon, A., Alturki, A.A., Bilitewski, B., Price, W.E., Nghiem, L.D. 2010. Effects of fouling and scaling on the retention of trace organic contaminants by a nanofiltration membrane: The role of cake-enhanced concentration polarisation. Sep. Purif. Technol., 73 (2), 256-263. 
473 Wang, X., Chen, Y., Yuan, B., Li, X., Ren, Y. 2014a. Impacts of sludge retention time on 474 sludge characteristics and membrane fouling in a submerged osmotic membrane 475 bioreactor. Bioresour. Technol., 161, 340-347.

476 Wang, X., Yuan, B., Chen, Y., Li, X., Ren, Y. 2014b. Integration of micro-filtration into 477 osmotic membrane bioreactors to prevent salinity build-up. Bioresour. Technol., 167, $478 \quad 116-123$.

479 Wintgens, T., Salehi, F., Hochstrat, R., Melin, T. 2008. Emerging contaminants and treatment 480 options in water recycling for indirect potable use. Water Sci. Technol., 57 (1), 99-107.

481 Wu, C., Spongberg, A.L., Witter, J.D., Sridhar, B.B.M. 2012. Transfer of wastewater 482 associated pharmaceuticals and personal care products to crop plants from biosolids 483 treated soil. Ecotoxicol. Environ. Safety, 85, 104-109. 


\section{LIST OF CAPTIONS}

Fig. 1: Schematic diagram of a laboratory-scale integrated O/MF-MBR hybrid system. Draw solution was replaced daily to avoid overflow and contaminant accumulation in the draw solution reservoir. High concentrated draw solution was added manually on a daily basis. Samples were taken from feed, bioreactor, MF permeate, and draw solution reservoir for analysis.

Fig. 2: Variation of mixed liquor conductivity and FO water flux with time. Experimental conditions: $\mathrm{HRT}=24 \mathrm{~h}$; DO concentration $=5 \pm 1 \mathrm{mg} / \mathrm{L}$; draw solution $=58.5 \mathrm{~g} / \mathrm{L} \mathrm{NaCl}$; cross-flow rate $=1 \mathrm{~L} / \mathrm{min}$ (i.e. cross-flow velocity $=9 \mathrm{~cm} / \mathrm{s}$ ); FO mode; temperature $=22 \pm 1$ ${ }^{\circ} \mathrm{C}$. Water flux of MF was adjusted from 1.6 to $2.6 \mathrm{~L} / \mathrm{m}^{2} \mathrm{~h}$ to compensate the flux decline of FO to keep a constant bioreactor working volume and HRT.

Fig. 3: Removal of (a) TOC, (b) TN, and (c) $\mathrm{PO}_{4}{ }^{3-}-\mathrm{P}$ by OMBR and MF-MBR channels of the integrated $\mathrm{O} / \mathrm{MF}-\mathrm{MBR}$ system.

Fig. 4: Variation of biomass concentration in the bioreactor with time.

Fig. 5: Measured TrOC concentrations in the feed, MF and FO permeates, and their removal by MF-MBR and OMBR channels of an integrated O/MF-MBR system. Error bars represent the standard deviation of eight measurements (once a week).

Fig. 6: Time-dependent removal of six hydrophilic and biologically persistent TrOCs (i.e. diclofenac, atrazine, carbamazepine, propoxur, fenoprop and clofibric acid) via MF-MBR and OMBR channels of the integrated O/MF-MBR system. 


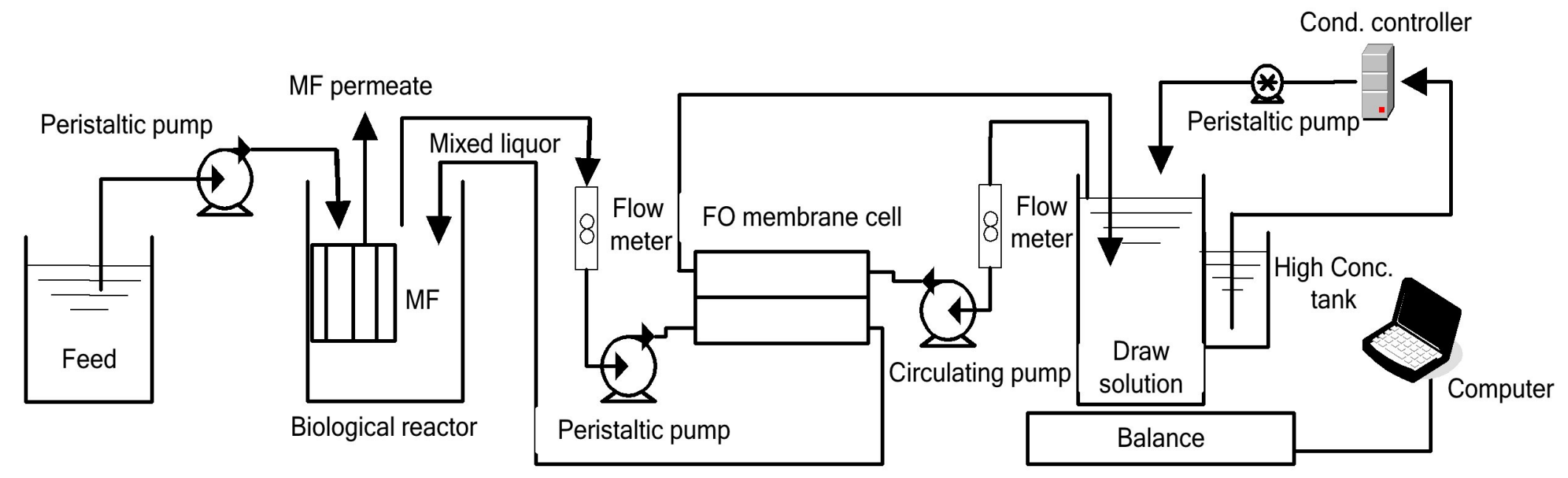

Figure 1 


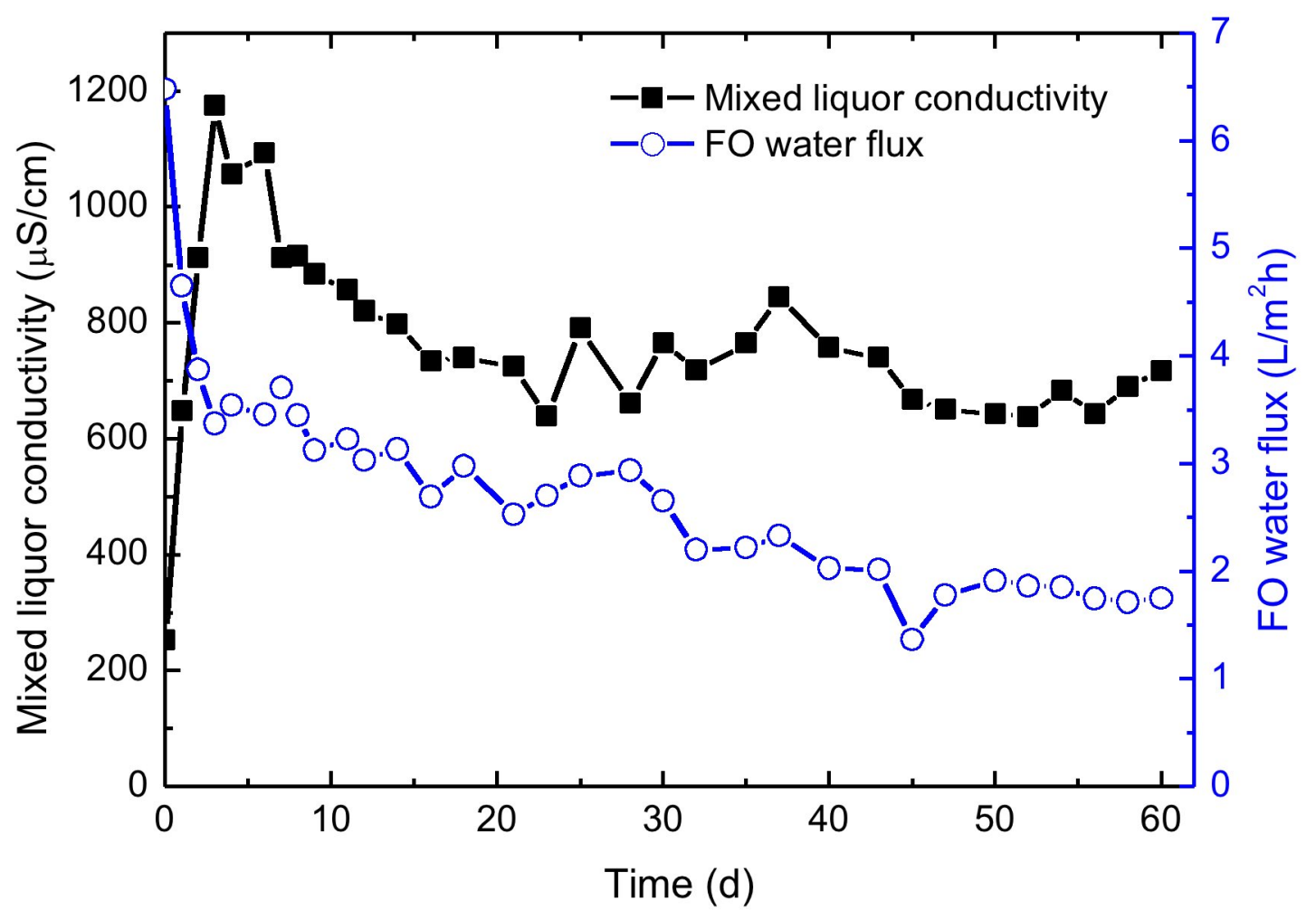

Figure 2 

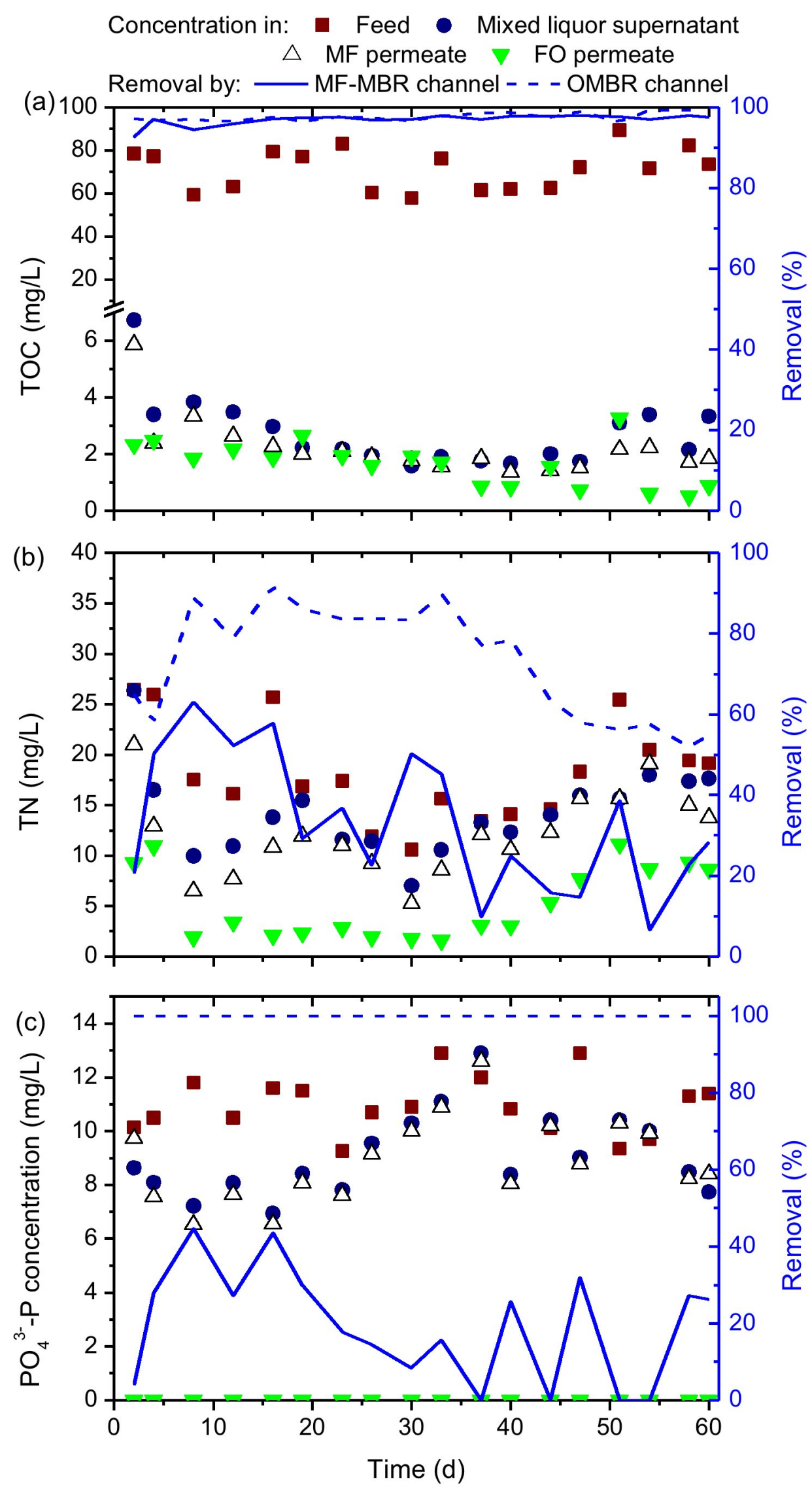

Figure 3 


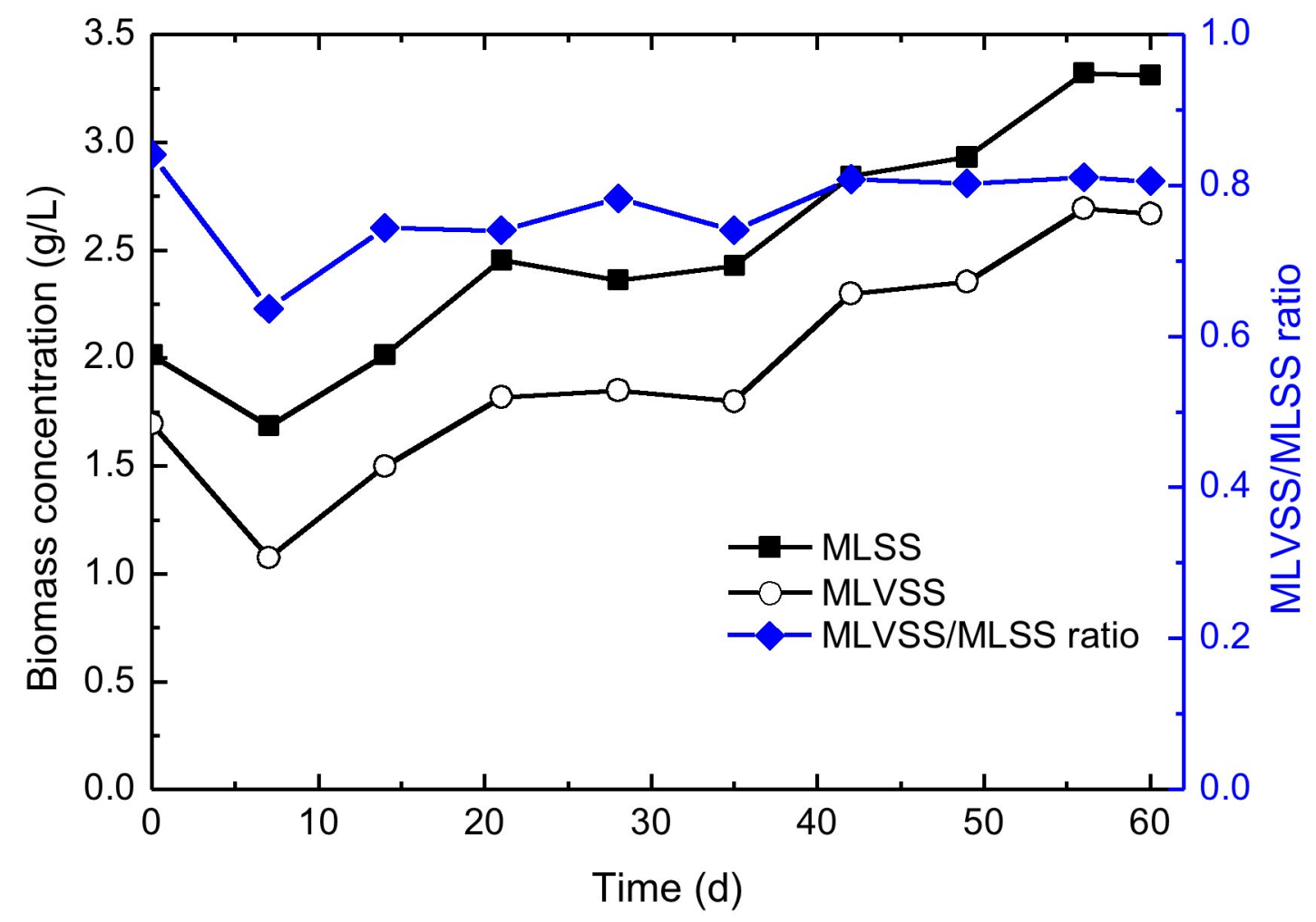

Figure 


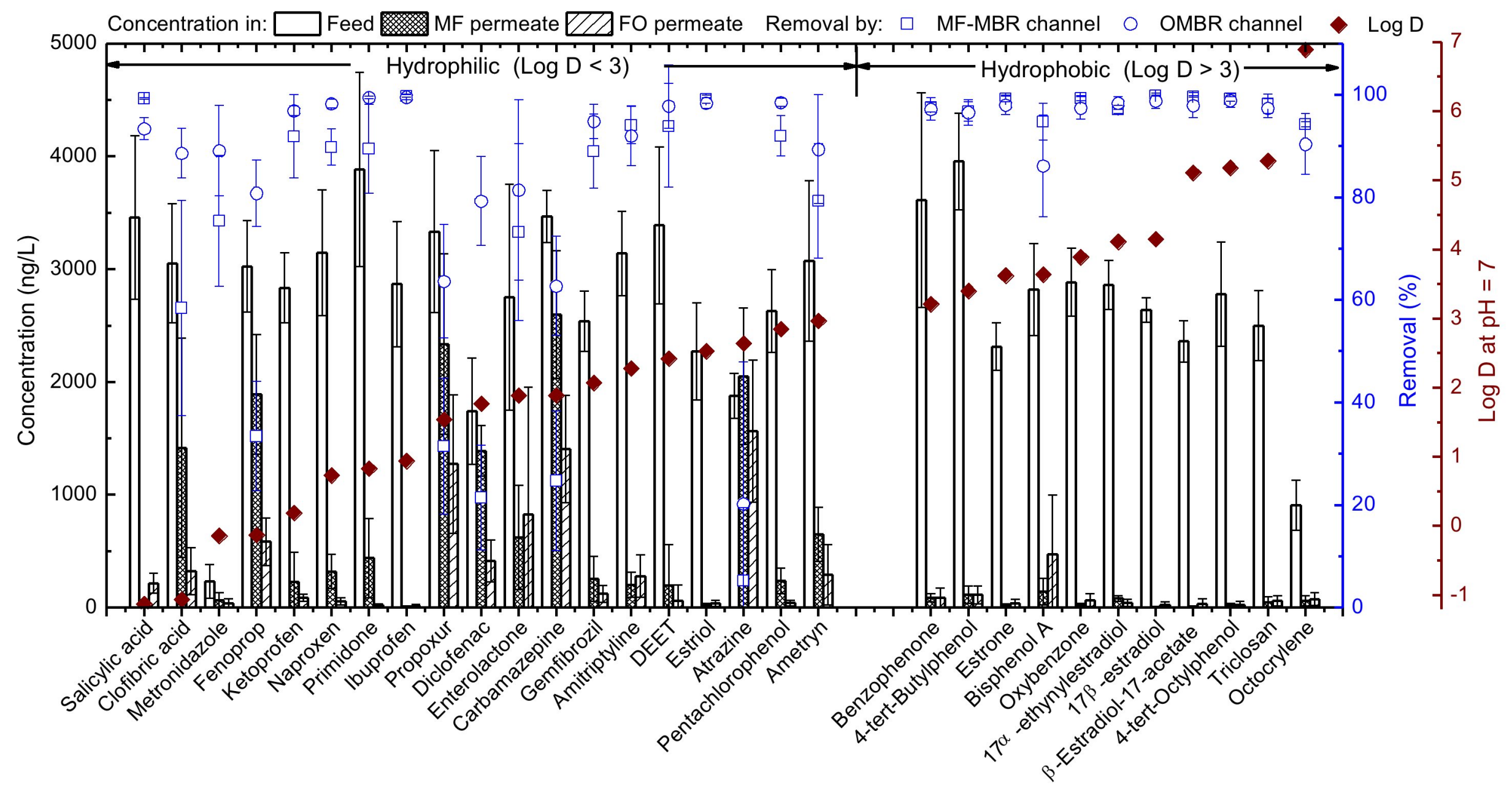

Figure 

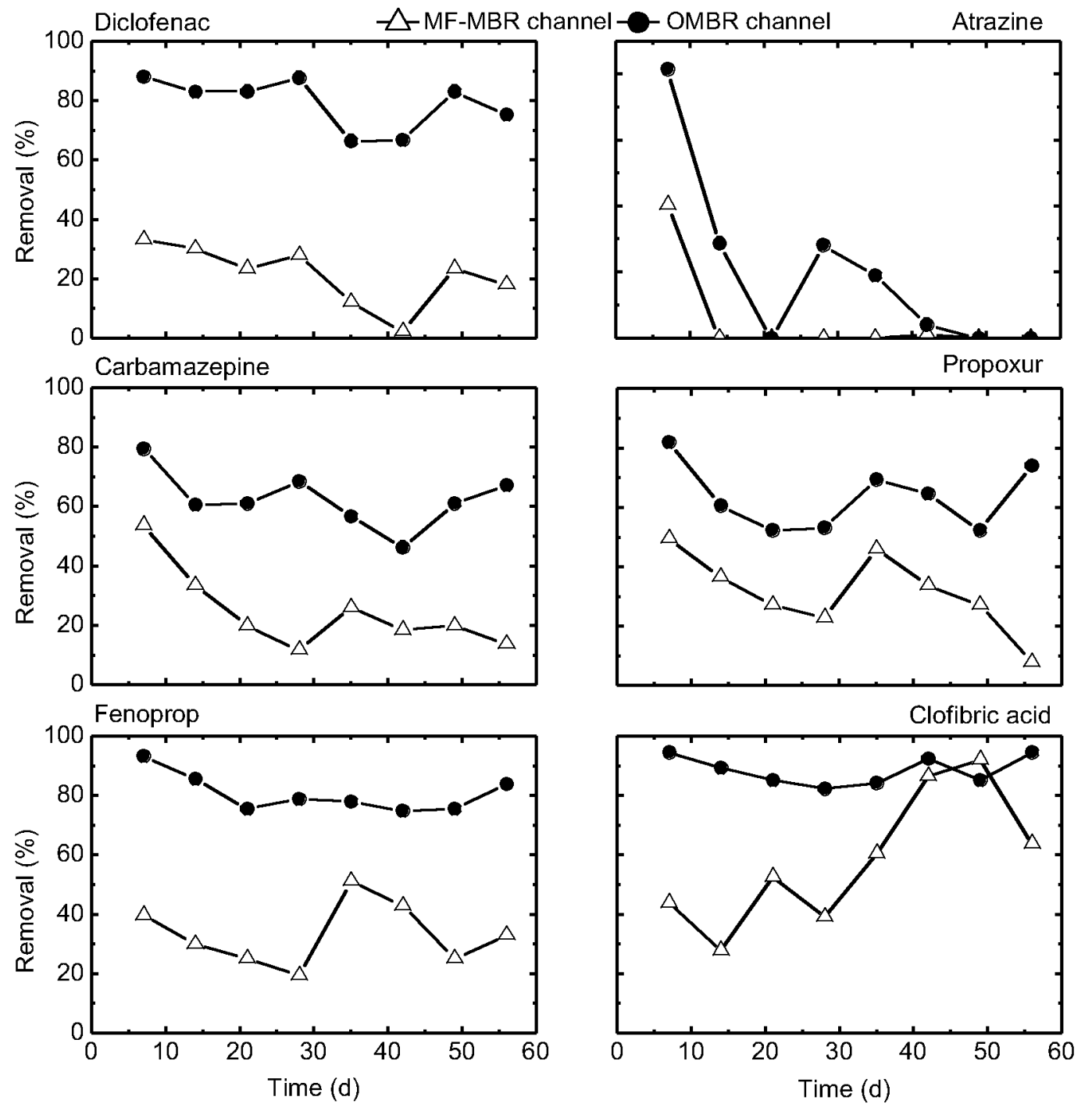

Figure 6 


\title{
The role of forward osmosis and microfiltration in an integrated osmotic-microfiltration membrane bioreactor system \\ Supplementary Data
}

\author{
Revised manuscript submitted to Chemosphere \\ April 2015 \\ Wenhai Luo ${ }^{a}$, Faisal I. Hai ${ }^{a}$, Jinguo Kang ${ }^{b}$, William E. Price ${ }^{b}$, Long D. Nghiem ${ }^{\text {a }}$, \\ Menachem Elimelech ${ }^{\mathrm{c}}$ \\ ${ }^{a}$ Strategic Water Infrastructure Laboratory, School of Civil Mining and Environmental \\ Engineering, University of Wollongong, Wollongong, NSW 2522, Australia \\ ${ }^{b}$ Strategic Water Infrastructure Laboratory, School of Chemistry, University of Wollongong, \\ Wollongong, NSW 2522, Australia \\ ${ }^{c}$ Department of Chemical and Environmental Engineering, Yale University, New Haven, CT \\ 06520-8286, United States
}

\footnotetext{
${ }^{*}$ Corresponding author: longn@uow.edu.au; Ph: +61 (2) 42214590.
} 
Table S1: Physicochemical properties of the selected trace organic chemicals.

\begin{tabular}{|c|c|c|c|c|}
\hline Compounds & $\begin{array}{l}\text { Chemical } \\
\text { formula }\end{array}$ & $\begin{array}{l}\log \mathrm{D} \\
\text { at } \mathrm{pH}=7\end{array}$ & $\begin{array}{l}\text { MW } \\
(\mathrm{g} / \mathrm{mol}) \\
\end{array}$ & Chemical structure \\
\hline Salicylic acid & $\mathrm{C}_{7} \mathrm{H}_{6} \mathrm{O}_{3}$ & -1.13 & 138.1 & \\
\hline Clofibric acid & $\mathrm{C}_{10} \mathrm{H}_{11} \mathrm{ClO}_{3}$ & -1.06 & 214.6 & \\
\hline Metronidazole & $\mathrm{C}_{6} \mathrm{H}_{9} \mathrm{~N}_{3} \mathrm{O}_{3}$ & -0.14 & 171.2 & \\
\hline Fenoprop & $\mathrm{C}_{9} \mathrm{H}_{7} \mathrm{Cl}_{3} \mathrm{O}_{3}$ & -0.13 & 269.5 & \\
\hline Ketoprofen & $\mathrm{C}_{16} \mathrm{H}_{14} \mathrm{O}_{3}$ & 0.19 & 254.3 & \\
\hline Naproxen & $\mathrm{C}_{14} \mathrm{H}_{14} \mathrm{O}_{3}$ & 0.73 & 230.3 & \\
\hline Primidone & $\mathrm{C}_{12} \mathrm{H}_{14} \mathrm{~N}_{2} \mathrm{O}_{2}$ & 0.83 & 218.3 & \\
\hline Ibuprofen & $\mathrm{C}_{13} \mathrm{H}_{18} \mathrm{O}_{2}$ & 0.94 & 206.3 & \\
\hline Propoxur & $\mathrm{C}_{11} \mathrm{H}_{15} \mathrm{NO}_{3}$ & 1.54 & 209.2 & \\
\hline Diclofenac & $\mathrm{C}_{14} \mathrm{H}_{11} \mathrm{Cl}_{2} \mathrm{NO}_{2}$ & 1.77 & 296.2 & \\
\hline Enterolactone & $\mathrm{C}_{18} \mathrm{H}_{18} \mathrm{O}_{4}$ & 1.89 & 298.33 & \\
\hline Carbamazepine & $\mathrm{C}_{15} \mathrm{H}_{12} \mathrm{~N}_{2} \mathrm{O}$ & 1.89 & 236.3 & \\
\hline Gemfibrozil & $\mathrm{C}_{15} \mathrm{H}_{22} \mathrm{O}_{3}$ & 2.07 & 250.3 & \\
\hline Amitriptyline & $\mathrm{C}_{20} \mathrm{H}_{23} \mathrm{~N}$ & 2.28 & 277.4 & \\
\hline DEET & $\mathrm{C}_{12} \mathrm{H}_{17} \mathrm{NO}$ & 2.42 & 191.3 & \\
\hline Estriol & $\mathrm{C}_{18} \mathrm{H}_{24} \mathrm{O}_{3}$ & 2.53 & 288.4 & \\
\hline
\end{tabular}




\begin{tabular}{|c|c|c|c|c|}
\hline Atrazine & $\mathrm{C}_{8} \mathrm{H}_{14} \mathrm{ClN}_{5}$ & 2.64 & 215.7 & . \\
\hline Pentachlorophenol & $\mathrm{C}_{6} \mathrm{HCl}_{5} \mathrm{O}$ & 2.85 & 266.4 & \\
\hline Ametryn & $\mathrm{C}_{9} \mathrm{H}_{17} \mathrm{~N}_{5} \mathrm{~S}$ & 2.97 & 227.3 & \\
\hline Benzophenone & $\mathrm{C}_{13} \mathrm{H}_{10} \mathrm{O}$ & 3.21 & 182.2 & \\
\hline 4-tert-Butylphenol & $\mathrm{C}_{10} \mathrm{H}_{14} \mathrm{O}$ & 3.4 & 150.2 & \\
\hline Estrone & $\mathrm{C}_{18} \mathrm{H}_{22} \mathrm{O}_{2}$ & 3.62 & 270.4 & \\
\hline Bisphenol A & $\mathrm{C}_{15} \mathrm{H}_{16} \mathrm{O}_{2}$ & 3.64 & 228.3 & \\
\hline Oxybenzone & $\mathrm{C}_{13} \mathrm{H}_{10} \mathrm{O}$ & 3.89 & 228.2 & \\
\hline $\begin{array}{l}17 \alpha- \\
\text { ethynylestradiol }\end{array}$ & $\mathrm{C}_{20} \mathrm{H}_{24} \mathrm{O}_{2}$ & 4.11 & 296.4 & \\
\hline $17 \beta$-estradiol & $\mathrm{C}_{18} \mathrm{H}_{24} \mathrm{O}_{2}$ & 4.15 & 272.4 & \\
\hline $\begin{array}{l}\beta \text {-Estradiol } \\
\text { acetate }\end{array}$ & $\mathrm{C}_{20} \mathrm{H}_{26} \mathrm{O}_{3}$ & 5.11 & 314.4 & \\
\hline 4-tert-Octylphenol & $\mathrm{C}_{14} \mathrm{H}_{22} \mathrm{O}$ & 5.18 & 206.3 & \\
\hline Triclosan & $\mathrm{C}_{12} \mathrm{H}_{7} \mathrm{Cl}_{3} \mathrm{O}_{2}$ & 5.28 & 289.5 & \\
\hline Octocrylene & $\mathrm{C}_{24} \mathrm{H}_{27} \mathrm{~N}$ & 6.89 & 361.5 & \\
\hline
\end{tabular}

Source: SciFinder Scholar (ACS) database. 
Table S2: Basic water quality in different units of O/MF-MBR (average \pm standard deviation ${ }^{*}$ )

\begin{tabular}{ccccc}
\hline \multirow{2}{*}{ Water parameters } & \multicolumn{4}{c}{ Contaminant concentration $(\mathrm{mg} / \mathrm{L})$} \\
\cline { 2 - 5 } & Feed & Mixed liquor supernatant & MF permeate & FO permeate \\
\hline TOC & $71.4 \pm 9.6$ & $2.7 \pm 1.2$ & $2.2 \pm 1.0$ & $1.7 \pm 0.8$ \\
TN & $18.3 \pm 4.9$ & $14.3 \pm 4.3$ & $12.2 \pm 4.1$ & $5.3 \pm 3.5$ \\
$\mathrm{NH}_{4}{ }^{-}-\mathrm{N}$ & $10.5 \pm 1.7$ & $2.5 \pm 1.4$ & $1.0 \pm 0.4$ & $0.6 \pm 0.3$ \\
$\mathrm{PO}_{4}{ }^{3-}-\mathrm{P}$ & $10.9 \pm 1.1$ & $9.1 \pm 1.5$ & $8.9 \pm 1.6$ & $0.0 \pm 0.0$ \\
\hline
\end{tabular}

*Standard deviation was calculated from 20 measurements (once every 3 days).

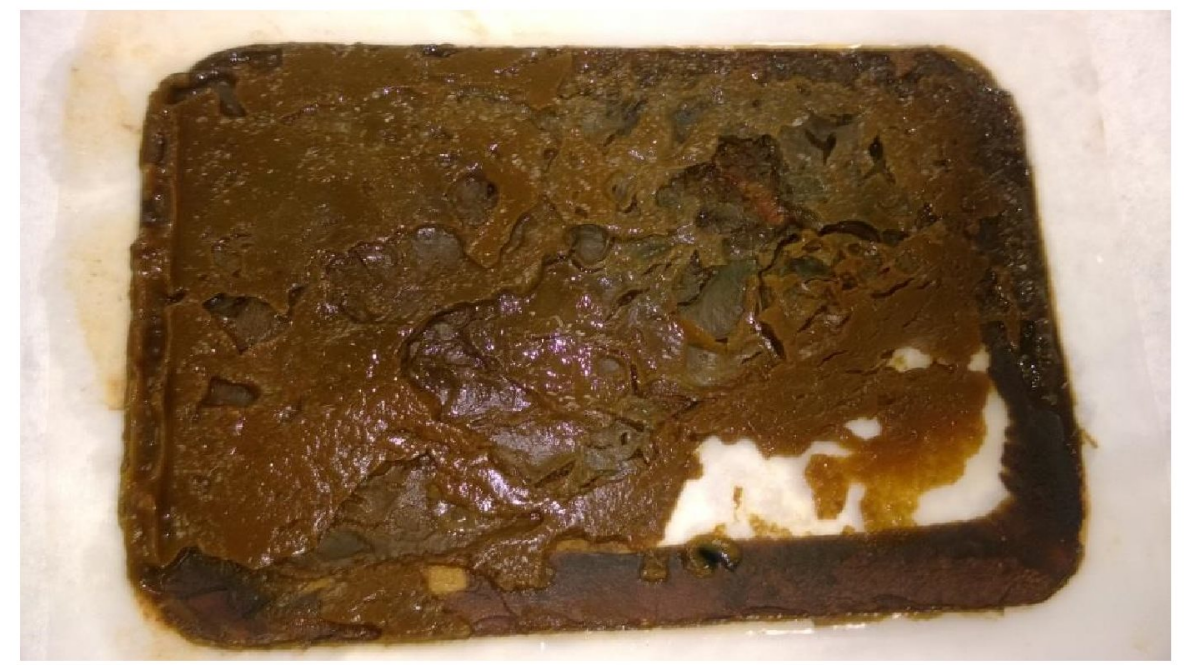

Fig. S1: Photograph of the FO membrane surface at the conclusion of the experiment. Membrane cleaning was not conducted. Experimental condition: CTA-FO membrane; FO mode; draw solution $=1 \mathrm{M} \mathrm{NaCl}$; cross-flow rate $=1 \mathrm{~L} /$ min (i.e. cross-flow velocity $=9$ $\mathrm{cm} / \mathrm{s}) ; \mathrm{HRT}=24 \mathrm{~h}$; DO concentration $=5 \pm 1 \mathrm{mg} / \mathrm{L}$; temperature $=22 \pm 1{ }^{\circ} \mathrm{C} ;$ MF water flux $=1.6-2.6 \mathrm{~mL} / \mathrm{min}$. 


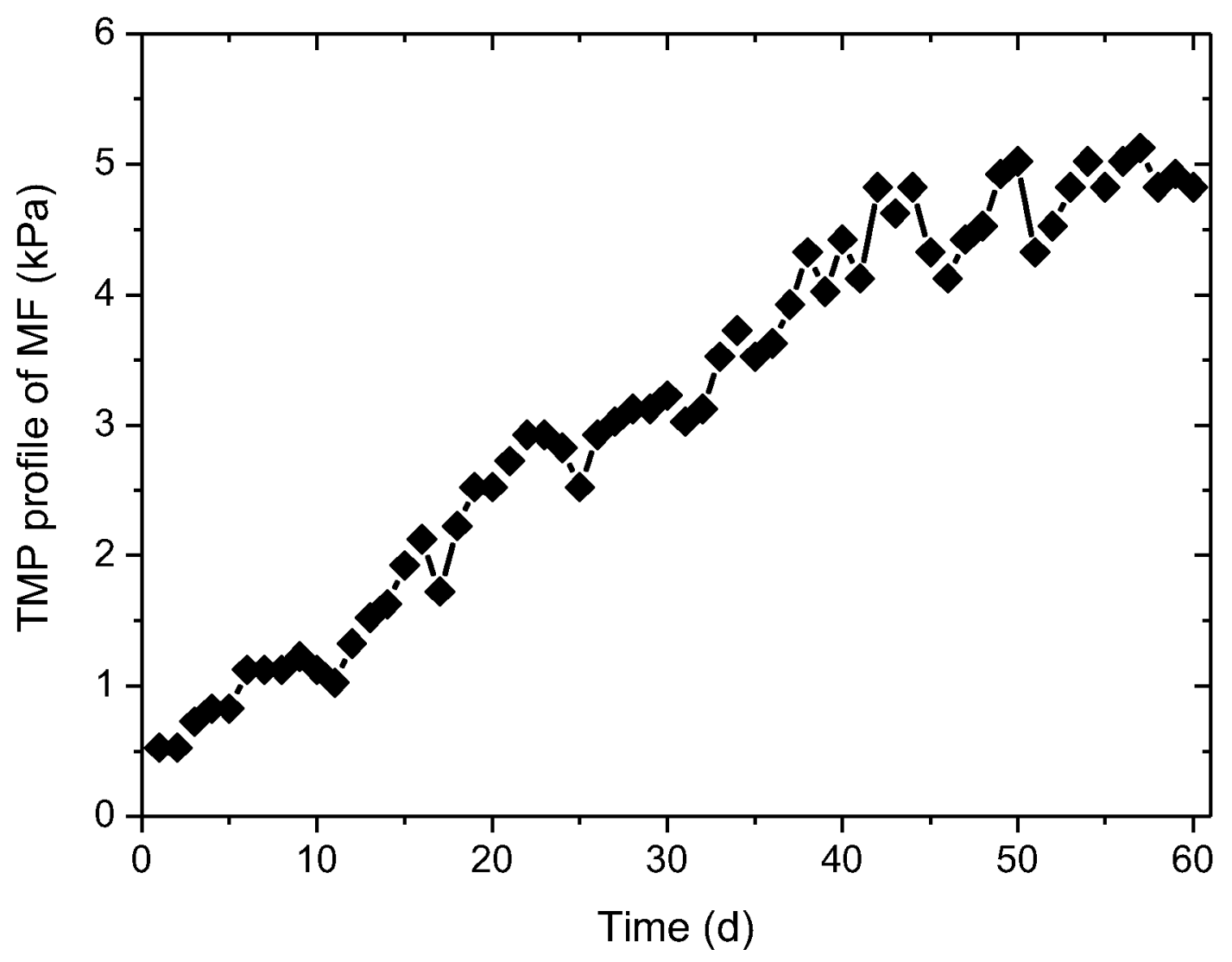

Fig. S2: The TMP profile of the MF membrane with time.

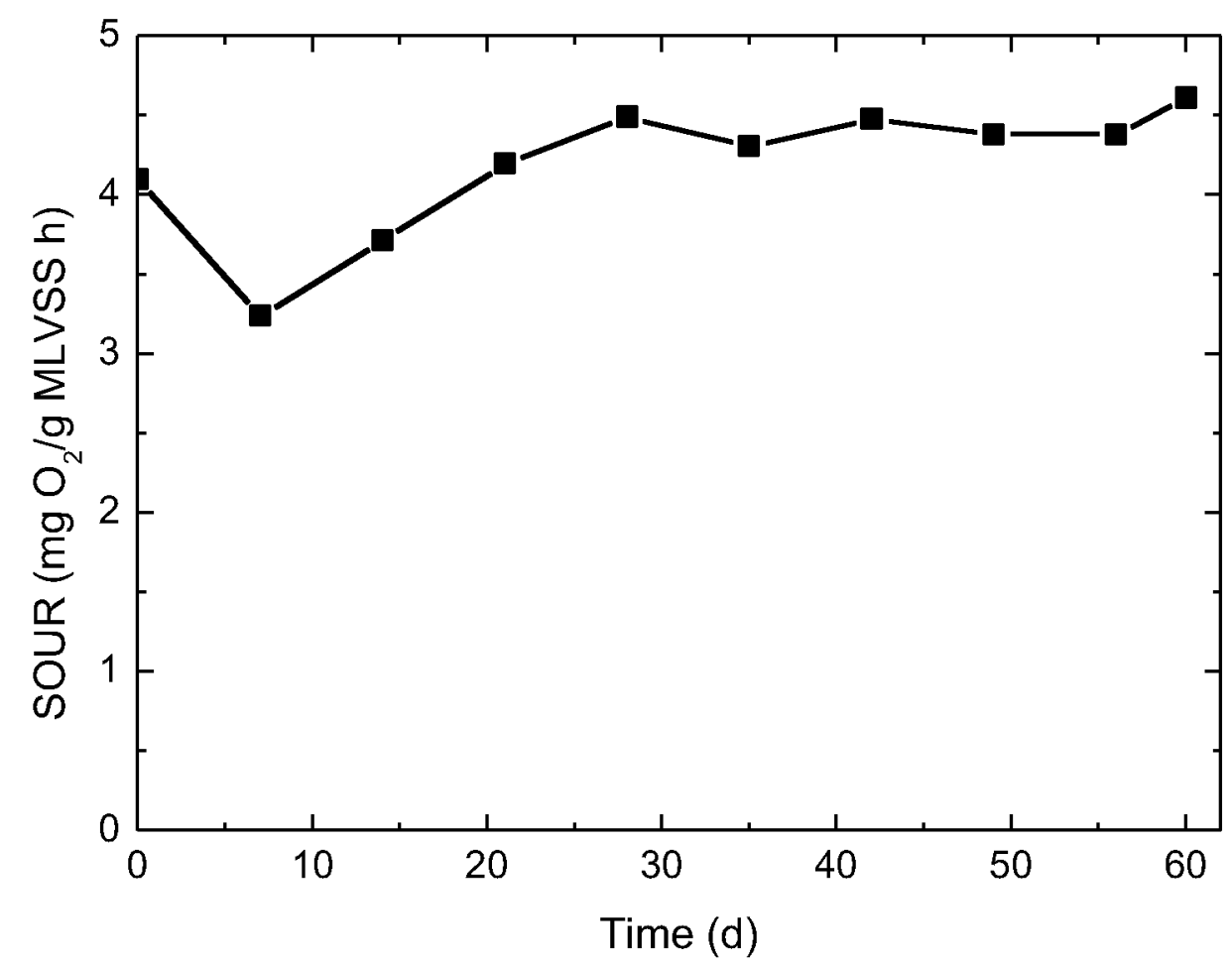

Fig. S3: SOUR of the activated sludge with time. 